\title{
International Consensus Statement for recommended terminology describing hysteroscopic procedures
}

\author{
J. Carugno ${ }^{1}$, G. Grimbizis 2 , M. Franchini ${ }^{3}$, L. Alonso 4 , L. Bradley, R. Campo 6 , U. Catena 7 , C. \\ De Angelis ${ }^{8}$, A. Di Spiezio Sardo 9 , M. Farrugia ${ }^{10}$, S. Haimovich ${ }^{11}$, K. Isaacson ${ }^{12}$, N. Moawad ${ }^{13}$, \\ E. SARidogan ${ }^{14}$, T.J. Clark ${ }^{15}$
}

An International Working Group of the American Association of Gynecologic Laparoscopists (AAGL), the European Society for Gynaecological Endoscopy (ESGE) and the Global Community of Hysteroscopy (GCH).

${ }^{1}$ Obstetrics, Gynecology and Reproductive Sciences Department, Minimally Invasive Gynecology Division, University of Miami, Miller School of Medicine. Miami, Florida, USA; ${ }^{2} 1^{\text {st }}$ Department of Obstetrics and Gynecology, Aristotle University of Thessaloniki, Tsimiski 51 Street, 54623, Thessaloniki, Greece; ${ }^{3}$ Demetra Infertility Center and Villa Cherubini Clinic, Firenze, Italy; ${ }^{4}$ Endoscopy Unit, Centro Gutenberg, Malaga, Spain; ${ }^{5}$ Cleveland Clinic. Cleveland Ohio, USA; ' Life Expert Centre, Leuven, Belgium; ' Department of Woman, Child, and Public Health, Fondazione Policlinico Universitario A Gemelli IRCCS, Rome, Italy; ${ }^{8}$ Department of Maternal and Child Health and Urological Sciences, "Sapienza" University of Rome, Rome, Italy; ' Department of Public Health, School of Medicine, University of Naples, "Federico II" Naples, Italy; ${ }^{10}$ Spencer Hospitals, Margate, United Kingdom; ${ }^{11}$ Hillel Yaffe Medical Center, Hadera, Rappaport Faculty of Medicine, Technion, Israel; ${ }^{12}$ Center for Minimally Invasive Gynecologic Surgery, Newton-Wellesley Hospital, Newton, MA; ${ }^{13}$ Division of Minimally Invasive Gynecologic Surgery, Department of Obstetrics and Gynecology University of Florida College of Medicine, Gainesville, Florida, USA; ${ }^{14}$ Reproductive Medicine Unit, Elizabeth Garrett Anderson Wing Institute for Women's Health, University College Hospital, NWI 2BU London, UK, ${ }^{15}$ Birmingham Women's and Children Hospital and University of Birmingham, Birmingham, B15 $2 T T, U K$.

$\dagger$ This article is not externally peer reviewed. The manuscript has been approved by the Executive Committees/Boards of AAGL, ESGE and GCH.

\$ This article is published simultaneously in FACTS, VIEWS \& VISION in Obgyn and Journal of Minimally Invasive Gynecology.

\section{Introduction}

Hysteroscopy is one of the commonest performed procedures in contemporary gynaecology and is considered the gold standard endoscopic procedure for the evaluation and treatment of women with intrauterine pathology (Gkrozou et al., 2015). Hysteroscopic procedures are conducted in a variety of health care facilities with or without the use of anaesthesia/analgesia or in a hospital operating room (theatre) with an anaesthetist in charge of pain management. The decision where and how to undertake hysteroscopic procedures depends upon a number of factors including the available infrastructure (staffing, equipment, facilities), preferences (both patient and clinician), the type of hysteroscopic procedure (i.e. feasibility, acceptability and effectiveness of diagnostic and operative procedures) and health economics (e.g. reimbursement, investment and cost-effectiveness). For diagnostic and simple operative procedures such as endometrial polypectomy, procedures performed outside of a formal operating room have been shown to be cost-effective, with a low complication rate, high rates of patient acceptability and patient's satisfaction (Kremer et al., 2000; Saridogan et al., 2010; Moawad et al., 2014; Clark et al., 2015; Cooper et al., 2015). More complex and prolonged procedures, such as hysteroscopic myomectomy and lysis of dense adhesions, are generally conducted in a hospital operating room with an anaesthetist present.

The structure and delivery of health care services vary across national health care systems, with differing credentialing requirements, funding, mechanisms for reimbursement and laws and regulations. These differences have hampered a clear understanding of how contemporary hysteroscopic services are currently being delivered globally and how best to do this. Specifically, there is no consensus regarding the terminology used to describe the different hysteroscopic procedures, 
including the setting in which they are performed and the model of care (i.e. need for elective hospital admi "undergoing hysteroscopic procedures. Terms such as "in-office" "outpatient", "ambulatory", "day-case", "in-patient", "operating room" are used frequently interchangeably without standardised definition or common understanding.

There is, thus, a pressing need for the implementation of a common terminology to describe hysteroscopic procedures that can be used uniformly in clinical practice and research. The creation and adoption of a standard nomenclature will be helpful for clinicians and patients by allowing the quality and outcomes of clinical practice to be qure ry practice to mere, the interpretation and generalisability of findings, as well as facilitating data syntheses (i.e. systematic reviews and meta-analyses)

Therefore, the American Association of Gynecologic Laparoscopists (AAGL), the European Society for Gynaecological Endoscopy (ESGE) and the Global Community of Hysteroscopy ( $\mathrm{GCH})$ formed an international working group of experts in hysteroscopy to develop a consensus statement of recommended terminology to use for describing different aspects of hysteroscopic procedures: (i) (i) pain management, (ii) the setting where procedures pre con length of stay and ned for adnission, (iv) the type of procedure and (v) the approach to hysteroscopy.

Methods

In June 2018, concerns about the lack of a standardised nomenclature to describe hysteroscopic procedures was identified by a group comprising of five expert hysteroscopists from Europe and the United States. The need to create a nomenclature that objectively and uniformly defined hysteroscopic procedures prompted this group to create a larger working group of leading international hysteroscopists to identify of leading in tenation

In December 2018, seventy gynaecologists with extensive experience in hysteroscopic procedures were selected to represent the international community. An email was distributed among the members of this group enquiring about identified areas of current hysteroscopic practice that, in their opinion, needed a common terminology. On January 31,2019 , a preliminary proposal regarding areas of hysteroscopic practice where standard nomenclature was needed, namely pain management, procedural setting the model of care, and approaches to hysteroscopy, was drafted. This broad, preliminary consensus was presented and discussed at the Global Hysteroscopy Congress in Barcelon Spain in June 2019, at the ESGE Annul Scientific Meeting in Thessaloniki, Greece in October 2019 nd at the Annual Global Congress of the AAGL in Vancouver, Canada in November 2019.

Following this wide consultation, the AAGL, the ESGE and the GCH created an internationa working group of 15 experts in hysteroscopy with the objective of revising the preliminary draft and prepare a consensus statement for terminology to be used for hysteroscopic procedures. Each scientific organisation contributed with five members in the group including practicing clinicians and esearchers who had demonstrated leadership an expertise hysteroscopic procedures.

A total of three online video meetings took place from April to June 2021 in which a fina greement for standardised nomenclature was obtained. The process for arriving at a consensu was as follows. Where there was consensus abo terminology for a particular area of hysteroscopic practice, the statements were adopted and revise only for editorial reasons. Where consensus could not be achieved, the proposed statements were removed, and members of the working group had the opportunity to provide verbal and written comments, suggestions, and to propose changes. These statements were revised accordingly The The

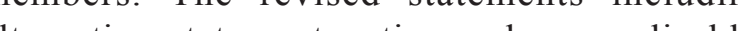
Iternative statement options where applicable, were disseminated in advance of the next onlin meeting and subsequently discussed in that forum. If voting failed to reach a consensus, the sam process was followed before and during the third and final online working group meeting. Where members could not attend the online meetings, their written opinions were sought in advance to

\section{Results}

The adoption and implementation of a commo erminology to standardise reporting of hysteroscopic procedures was proposed to cover five domains; pain management, healthcare setting, model of care, type of hysteroscopic procedure an the hysteroscopic approach to the uterine cavity. A summary of the terminology is given in Table I, and more detailed descriptions are provided in the subsequent sections.

\section{Pain managemen}

Technological advances have led to the miniaturisation of hysteroscopes and ancillary

Table I. - Overview of terminology for hysteroscopy.

\begin{tabular}{|c|c|}
\hline Pain management & $\begin{array}{ccc} & \text { Level 1 } & \\
\text { - } & \text { Level 2 } & \\
\text { - } & \text { Level 3 } & \\
& \bullet & \text { Level 3(a) } \\
& \cdot & \text { Level 3(b) } \\
\text { - } & \text { Level 4 } & \\
\text { - } & \text { Level 5 } & \end{array}$ \\
\hline Setting & $\begin{array}{ll}\text { - } & \text { Office } \\
\text { - } & \text { Outpatient clinic } \\
\text { Operating room }\end{array}$ \\
\hline Model of care & $\begin{array}{ll}\dot{\bullet} & \text { Office } \\
\dot{5} & \text { Outpatient } \\
\text { : } & \text { Ambulatory } \\
\dot{5} & \text { Extended Recovery } \\
\text { Inpatient }\end{array}$ \\
\hline Type of procedure & $\begin{array}{ll}\text { - } & \text { Diagnostic hysteroscopy } \\
\text { Operative hysteroscopy }\end{array}$ \\
\hline Approach of procedure & $\begin{array}{ll}\text { - } & \text { Vaginoscopy } \\
\text { Speculum assisted }\end{array}$ \\
\hline
\end{tabular}

Table II. - Levels of pain management used during hysteroscopic procedures*

\begin{tabular}{|l|l|}
\hline Level 1 & No medication or the use of oral non-sedative medication \\
\hline Level 2 & Local anaesthetic to the genital tract \\
\hline $\begin{array}{c}\text { Level 3 } \\
\text { Level 3 (a) } \\
\text { Level 3 (b) }\end{array}$ & $\begin{array}{c}\text { Conscious sedation } \\
\text { - Oral or inhalational medications with a sedative effect }\end{array}$ \\
\hline Level 4 & Parenteral medications with a sedative effect \\
\hline Level 5 & Genenal anesthesia \\
\hline $\begin{array}{l}\text { *Pain managesthenthia should be defined according to the highest level of intervention used to control } \\
\text { pain if combined therapies are used. }\end{array}$ \\
\hline
\end{tabular}

instrumentation, which has facilitated the conduct of procedures without the need for anaesthesia or with the use of local genital tract anaesthesia alone. The feasibility of conducting procedures without the need for conventional general or regional anaesthesia is dependent upon several factors both clinical and non-clinical and these include the type of procedure, patient preferences, clinician expertise, the available instrumentatio and infrastructure and how health services are reimbursed and regulated.

Thus, the management of pain is a key consideration when undertaking hysteroscopic procedures and needs to be clearly and consistently reported. A hierarchical description of pain management, consisting of five levels, is recommended. (Table II)

\section{Setting}

There is currently no common understanding on the best terminology to define the setting in which hysteroscopic procedures are carried out. Term such as "in-office", "outpatient" "ambulatory", "day-case", "in-patient", "operating room" are used without standardised definition and often incorporate both the place (facility) where procedures are conducted and whether patients are admitted an how long they stay for.

In order for a clearer understanding of the procedural situation, it is recommend that the setting is defnedin aligmentwith th "Interntions Association for Ambulatory (Day) Surgery (IAAS) Suggested International Terminology and Definitions" (International Association for Ambulatory Surgery, 2003) and according to the level of pain management that is feasible in the facility where the hysteroscopic procedure is performed (Table III). This categorisation recognises that the level of pain management is no related to the environment (hospital, surgical center, community clinic or office) where the hysteroscopic procedure is performed and is not dependent upon the need for admission or dictated by the planned length of stay.

\section{Model of care}

To enable clarity over the definition of setting for hysteroscopy and ensure consistency with the 
Table III. - Definitions of the setting for hysteroscopy

\begin{tabular}{|l|l|}
\hline Office & $\begin{array}{l}\text { The hysteroscopic procedure is performed in a medical practitioner's professional premises where pain } \\
\text { control up to level 3(a) can be administered. }\end{array}$ \\
\hline Outpatient Clinic* & $\begin{array}{l}\text { The hysteroscopic procedure is performed in a health care facility for the management of outpatients e.g. } \\
\text { hospital, community clinic or a freestanding surgical centre where pain control up to level 3(a) can be } \\
\text { administered. }\end{array}$ \\
\hline Operating Room & $\begin{array}{l}\text { The hysteroscopic procedure is performed in a fully equipped operating theatre where pain control up to } \\
\text { level } 5 \text { can be administered }\end{array}$ \\
\hline $\begin{array}{l}\text { *In some countries, in compliance of local legislation, pain management up to level } 3(\mathrm{~b}) \text { can be administered in an office or outpatient room setting. } \\
\text { In such exceptional circustances, the esetting can be described as office or outpatient clinic rather than operating room, but the reported clinical data } \\
\text { should report that level 3(b) pain management was used including type of pain management administered and route of administration. }\end{array}$ \\
\hline
\end{tabular}

Table IV. - Model of care for hysteroscopy.

\begin{tabular}{|l|l|}
\hline Office* & $\begin{array}{l}\text { The model of care will be considered as "office" when the patient arrives and leaves a medical practitioner's } \\
\text { professional premises, which provides an appropriately designed, equipped and serviced room(s), on the } \\
\text { same calendar day. }\end{array}$ \\
\hline Outpatient" & $\begin{array}{l}\text { The model of care will be considered as "outpatient" when the patient arrives and leaves the facility } \\
\text { (outpatient clinic / department of a hospital, community clinic or a freestanding surgical centre (public or } \\
\text { private)) on the same calendar day. }\end{array}$ \\
\hline Ambulatory & $\begin{array}{l}\text { The model of care will be considered as "ambulatory" when the patient undergoing the hysteroscopic } \\
\text { procedure is admitted to a facility (hospital or surgical centre) and discharged on the same calendar day. }\end{array}$ \\
\hline Extended Recovery & $\begin{array}{l}\text { The model of care will be considered as "extended recovery" when the patient is admitted to a facility } \\
\text { (hospital or surgical centre) with discharge the following calendar day with a length of stay of less than } 24 \\
\text { hours. }\end{array}$ \\
\hline Inpatient & $\begin{array}{l}\text { The model of care will be considered "inpatient" when the patient is admitted to a facility (hospital or surgical } \\
\text { center) and discharged not sooner than the following calendar day, with a length of stay of at least } 24 \text { hours. }\end{array}$ \\
\hline "In the United States the term office and outpatient are used interchangeably as regards the model of care. \\
\hline
\end{tabular}

IAAS definitions (International Association for Ambulatory Surgery, 2003), it is recommended that the need for admission, the length of stay and type(s) of facility should be used to define the "model of care" under which the hysteroscopic procedure is undertaken. (Table IV).

4. Type of procedure

Hysteroscopic procedures can be diagnostic and / or therapeutic (operative). Diagnostic procedures aim to visualise the uterine cavity to detect or exclude endometrial and structural abnormalities (congenital and acquired) with or without tissue ampling (blind or directed biopsy). Operative etrial uterine pathologies with the aim of providing a therapeutic benefit by alleviating gynaecological symptoms as well as allowing histological

analysis of removed tissue. The suggested terminology recommended to distinguish the type of hysteroscopic procedure is shown in Table V.

5. Approach of the hysteroscopic procedure

The traditional approach conducting hysteroscopy to access the uterine cavity consists of inserting vaginal speculum to visualise the cervix, which is then grasped with a toothed forceps (tenaculum/vulsellum) to provide counter traction when dilatating the cervical canal an subsequently introducing the hysteroscope through the cervical canal and into the uterin cavity under direct visualisation. This technical approach was consolidated after the introduction of hysteroscopy to routine gynaecological practice in the 1990's when procedures were generally conducted exclusively under general or regional

Table V. - Type of hysteroscopy

\begin{tabular}{|l|l|}
\hline Diagnostic hysteroscopy" & $\begin{array}{l}\text { A hysteroscopic procedure to evaluate the uterine cavity / cervical canal with or without targeted biopsy } \\
\text { (under hysteroscopic visualisation). }\end{array}$ \\
\hline Operative Hysteroscopy" & $\begin{array}{l}\text { A hysteroscopic procedure to treat uterine pathology, or symptoms arising from the uterus, under direct } \\
\text { hysteroscopic visualisation using hysteroscopic instruments. }\end{array}$ \\
\hline $\begin{array}{l}\text { * The use of hysteroscopy is not intended for the evaluation and management of the patient with cervical cancer or its precursors. } \\
\text { ** "“lind" intratauterine procedures, such as an endometrial ablation procedure without hysteroscopic visualisation, insertion of fintrauterine hormonal } \\
\text { devices etc. should not be considered an operative hysteroscopy according to the proposed classification. However, studies describing such uterine } \\
\text { procedures should report pain management, setting and model of care as described in the preceding sections. }\end{array}$ \\
\hline
\end{tabular}

Table VI. - Approach to hysteroscopy.

\begin{tabular}{|l|l|}
\hline Vaginoscopic & The hysteroscope is steered into the cervical canal without the use of a speculum and/or stabilising
\end{tabular}

the cavity.

$\begin{array}{ll}\text { Speculum assisted } & \text { The hysteroscope is steered into the cervical canal with the use of a speculum and/or stabilising forceps to } \\ \text { facilitate the visualisation of the crvix and entry into the cervical canal and uterine cavity. }\end{array}$ facilitate the visualisation of the cervix and entry into the cervical canal and uterine cavity.

anaesthesia. Advances in surgical technology, and in particular miniaturisation of endoscopes and ancillary instrumentation, has allowed hysteroscopy to be performed without the need for vaginal instrumentation because cervical dilatation is not routinely required. This progression allowed hysteroscopy to be undertaken without the requirement for an anaesthetist or a forma hospital operating room (theatre) and hysteroscopy conducted in more convenient and accessible office and outpatient clinic settings became established.

Once office/outpatient clinic hysteroscopy became established, some practitioners began using techniques which did not require convention vaginal instrumentation with specula and forceps (Bettocchi and Selvaggi, 1997; Shama et al., 2005; Coper al, 2010; Snith et al, 2019; De Silva Silva et al., 2020). The hysteroscope was passed directly into the vagina, avoiding unnecessary pain induced by vaginal distension and manipulation/ traction of the cervix. Subsequent clinical trials and data syntheses have demonstrated the benefits of such approaches in terms of reducing pain an enhancing patient experience (Smith et al., 2019; De Silva et al., 2020).

It is recommended that the approach to hysteroscopy, namely how the cervix is visulized and accessed to enable entry into the cervical canal and uterine cavity, is defined according to whether vaginal instrumentation is used or not (Table VI).

\section{Documentation and reporting}

A proforma to report hysteroscopic procedures according to this nomenclature is presented in Table VII.

Discussion

Hysteroscopy is considered the gold standard procedure for the diagnosis and management of women with intrauterine pathology and is one of the most common interventions in contemporary gynaecological practice (Gkrozou et al., 2015). Despite its ubiquity, there has been a lack of consensus when describing hysteroscopic procedures such that multiple terms are used across the internationat community with clear definition as to what they mean. of clarity has caused confusion and hindered reliable interpretation of clinical data and scientific communications pertaining to the practice of hysteroscopy. Moreover, robust comparisons of hysteroscopic procedures have been compromised, as have the ability to synthesise data in systematic quantitative reviews to help inform clinica practice. By producing standard nomenclature for 5 fundamentally important areas of hysteroscopic practice, we hope that practitioners will find this consensus statement relevant and easy to adop when reporting hysteroscopic procedures in both daily clinical practice and research studies. To aid use of this nomenclature, a standard proforma ha been provided to report hysteroscopic practice in a systematic way according to the pain management utilised, the proced utised the proceder adopted, the type of procedure and finally the approach to conducting the hysteroscopy (se Table VII). This reporting proforma is highly recommended to be used in publications to allow comparisons and future meta-analysis.

Contemporary hysteroscopy is performed in a variety of health care settings using differen methods of pain control. Hysteroscopic procedures using smaller diameter endoscopes and improved operative technologies, are increasingly being

Table VII. - Proforma for documenting and reporting

hysteroscopy*.
\begin{tabular}{|l|r|l|r|}
\hline Setting & & Pain management & \\
\hline Office & $\square$ & $\begin{array}{l}\text { Level 1 } \\
\text { Level 2 }\end{array}$ & $\square$ \\
\hline Outpatient Clinic & $\square$ & $\begin{array}{l}\text { Level 3 (a) } \\
\text { Level 3 (b) }\end{array}$ & $\square$ \\
\hline Operating Room & $\square$ & $\begin{array}{l}\text { Level 4 } \\
\text { Level 5 }\end{array}$ & $\square$ \\
\hline Approach & & Type & $\square$ \\
\hline Vaginoscopic & $\square$ & Diagnostic & $\square$ \\
\hline Speculum Assisted & $\square$ & Operative & $\square$ \\
\hline Model of care & & & \\
\hline No admission & & Admission & \\
\hline Office procedure & $\square$ & Ambulatory procedure & $\square$ \\
\hline Outpatient procedure & $\square$ & $\begin{array}{l}\text { Extended recovery } \\
\text { procedure }\end{array}$ & $\square$ \\
Inpatient procedure & $\square$ \\
\hline
\end{tabular}


in variety of facilities. Avoidance of regional or general anaesthesia is associated with a decrease rate of complications, faster recovery times, high rates of acceptability, equivalent effectiveness and greater cost-effectiveness (Cooper et al., 2015; Diwakar et al., 2016). However, pain associated with such hysteroscopic procedures limits the feasibility of such procedures and can adversely affect patient experience (Zupi et al., 1994; del Valle et al., 2016; Paulo et al., 2016; Amer-Cuenca et al., 2020). Alternatively, the use of highly sedative medications, or regional/ general anaesthesia necessitates the presence of an anaesthetist and invariably a formal operating room. Thus, the working group agreed that in modern hysteroscopy it is important to clearly define and report and the procedural setting. Consensus was reached about a hierarchy of pain control measures relevant to hysteroscopy and that the procedural setting should be defined according to the level of pain control used in conjunction with the type of facility where the hysteroscopy was undertaken. To allow greater clarity as regard to what was meant by procedural setting, the length of stay and plan for admission to a specific health care facility did not inform the definition of setting, but rather was kept distinct and reported within a separate "model of care" category the was separated

The working group felt that the type of hysteroscopic procedure should be dichotomised into diagnostic procedures and those where the hysteroscope was directly used to treat uterine conditions or remove intrauterine pathologies. Finally, the group believed that the approach to hysteroscopy, namely the technique to visualize and traverse the cervical canal to access the uterine cavity should be reported in a standard fashion. This was in recognition of the miniaturisation of endoscopes and ancillary equipment over time that has facilitated hysteroscopic procedures being performed without the need for any other vaginal instrumentation, namely vagin specula or forceps applied to the intravaginal cervix (Bettocchi and Selvaggi, 1997, Sharma et a., 2005). These, "vaginoscopic" approaches are quicker and less painful (Smith et al., 2019; De Silva et al., 2020).

The strengths of this consensus statement include the initial wide, international consultation to identify key areas where common definitions or hysteroscopic practice were needed and the subsequent formation of a working group of practicing expert clinicians and researchers by the three leading organisations in the field. This group produced and finalised the standard nomenclature by consensus following several iterations of the proposed statements and classifications until overall consensus was reached. Weaknesses of our approach include that we did not conduct a systematic literature search to identify published literature pertaining to standardised reporting of hysteroscopy. However, our literature searches did not find such papers and our international panel of leading experts in hysteroscopy were unaware of any standard nomenclature. Despite the international make-up of the working group, not all geographic areas were represented. Furthermore, our consensus was not reached using a highly
structured approach, such as adoption of a formal Delphi process (Jones and Hunter, 1995). These Dethodological we ( . erminology. However, a consensus method very close to the expert panel technique was used as clearly described in the material and methods session and we believe that the group had adequate international representation and enough clinical and research expertise, in hysteroscopy to be cognizant of the current variations in terminology and reporting within global clinical practice and the international, published medical literature.

We anticipate that wide, international adoption of this standard terning will vastly enhance Whis enhance this will facilitate better understanding of clinical practice, the conduct and feasibility of techniques, and the cost-effectiveness of hysteroscopic interventions. Clinical and research collaborations will be facilitated, and data syntheses supported to robustly inform clinicians and patients.

\section{Conclusion}

Hysteroscopy is the gold standard technique for the evaluation and management of uterine disorders and is widely used in modern gynaecological practice. However, a clear definition and understanding of the terminology used to describe hysteroscopic procedures is lacking. The production of this international consensus statement for terminology to describe hysteroscopic procedures, covering pain management, setting, model of care, type of procedure and hysteroscopic approach, has the potential to enable more effective communication for both clinical and research purposes with the ultimate aim of improving patient care and clinical outcomes.

A summary of the standard terminology describing hysteroscopic procedures is provided in the appendix
Disclaimer: The present terminology of hysteroscopic credentialing, requirements, and laws that are currently in place at the facilities in which the hysteroscopic procedures are performed, acknowledging that they are different and specific in every healthcare system of each nation. This working group has produced it nomenclature cognizant of variations in clinical practice and the variation in the structure of health care system across the globe. The working group encourages translation of the proposed definitions into relevan languages, including necessary interpretation applicable to individual countries and health care systems.

Acknowledgements: This working group would like to thank the initial large group of expert hysterosocpist who participated in the elaboration of the initia

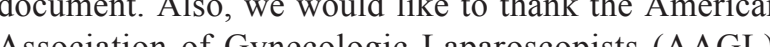
Association of Gynecologic Laparoscopists (AAGL), (ESGE) and the Global Community (GCH) for the Global Coning of Hysteroscopy GCH) for hir support during the production of this

Funding: There was no external funding of the development process or manuscript production.

Conflicts of interest: The authors have no financial conflicts to disclose regarding the content of this manuscript.

Contribution to authorship:

JC - Contributed to all working group discussion and manuscript writing.

GG - Contributed to all working group discussions and helped draft all iterations of the manuscript. TJC - Contibuted to all working group discussions MF - Contributed to the cretion of initial work Mr Cont to the the creation of contributed to all working gorp disclission ar manuscript writing.

LA - Contibuted to the creation of initial work contributed tiscussion an LB - Contibut to al

LB - Contributed to all working group discussion and review of the final manuscript.

RC - Contributed to all working group discussion and UC - Contibut to all work.

UC - Contibuted to all working group discussion and DC-Contributed to all working

DC - Coup discussion and rDS - Contibuted to the crear

theation of initial work wing group discussion and reviow of the final wanuscript.

working group discussion SH - Contrib to to the cript.

Contributed to all worition of initial work Coniew of the fin working KI Contributed to all working review of the final manuscript.
$\mathrm{NM}$ - Contributed to all working group discussion and review of the final manuscript.

ES - Contributed to all working group discussion and review of the final manuscript.

References

Amer-Cuenca JJ, Marín-Buck A, Vitale SG et al. Nonpharmacological pain control in outpatient hysteroscopies.

Bettochi S, Selvaggi L. A vaginoscopic approach to reduce
the pain of office hysteroscopy. J Am Assoc Gyneco Laparosc. 1997:4:255-8.

Clark TJ, Middleton LJ, Cooper NA et al. A randomised controlled trial of Outpatient versus inpatient Poly Technol Assess 2015:19:1-194

Cooper NA, Clark TJ, Middleton L et al. Outpatient versus inpatient uterine polyp treatment for abnormal uterine bleeding: randomised controlled non-inferiority study.

Cooper NA, Smith P, Khan KS et al. Vaginoscopic approach
to outpatient hysteroscopy: a systematic review of the to outpatient hysteroscopy: a systematic
effect on pain. BJOG. 2010;117: 532-9.

De Silva PM, Carnegy A, Smith PP et al. Vaginoscopy for office hysteroscopy: A systematic review \& meta-analysi

De Silva PM, Mahmud A, Smith PP et al Analgesia for office hysteroscopy: a systematic review and meta-analysis. Minim Invasive Gynecol. 2020;27:1034-47.

del Valle C, Solano JA, Rodriguez A et al. Pain managemen in outpatient hysteroscopy. Gynecol Minim Invasive The

wakar L, Roberts TE, Cooper NA et al. L. An economic evaluation of outpatient versus inpatient polyp treatmen
for abnormal uterine bleeding. BJOG. 2016;123:625-31. Grozou F, Dimakopoulos G, Vrekoussis T et al. Hysteroscopy in women with abnormal uterine bleeding: a meta-analysi Obstet. 2015;291:1347-54.

International Association for Ambulatory Surgery. Ambulatory (Day) surgery vocabulory \& precisions. 2003. https://iaas-
med com/files/historical/IAAS definitions pdf med.com/files/historical/IAAS_definitions.pdf
Jones J, Hunter D. Consensus methods for medical and health
services research. BMJ. 1995; 311:376-80.

services research. BMJ. 1995 ; 31:376-80.
Kremer C, Duffy S, Moroney M. Patient satisfaction with outpatient hysteroscopy versus day case hysteroscopy randomised controlled trial. BMJ. 2020;320:279-82.

Moawad NS, Santamaria E, Johnson M et al. and J. Cost-
effectiveness of office hysteroscopy for abnormal uterine effectiveness of office hysteroscopy for
bleeding. JSLS. 2014;18:e2014.00393.

Paulo AAS, Solheiro MHR, Paulo COS. What proportion of women refers moderate to severe pain during office hysteroscopy with a mini-hysteroscope? A systematic
review and meta-analysis. Arch Gynecol Obstet.

Saridogan E, Tilden D, Sykes D et al. Cost-analysis comparison
of outpatient seeof outpatient see-and-treat hysteroscopy service with other
hysteroscopy service models. J Minim Invasive Gynecol. 2010;17:518-25,

harma M, Taylor A, di Spiezio Sardo A et al. Outpatien
hysteroscopy: traditional versus the 'no-touch" technique. hysteroscopy: traditiona

mith P, Kolhe S, O'Connor S et al. Vaginoscopy Agains Standard Treatment: a randomised controlled trial. BJOG Zupi E, Luciano AA, Marconi D et al. The use of topical biopsy. J Am Assoc Gynecol Laparosc. 1994;1:249-52. 


\section{Appendix - Recommended nomenclature for reporting hysteroscopy}

(Summary of the five domains to be recorded when reporting clinical data relating to hysteroscopic procedures for quality assurance or research publications / presentations)

\section{Domain 1: Pain management}

Pain management is defined according to a hierarchy of escalating pain management strategies (five levels) for hysteroscopic procedures.

\begin{tabular}{|l|l|}
\hline Level 1: & No medication or the use of oral non-sedative medication \\
\hline Level 2: & Local anaesthetic to the genital tract \\
\hline Level 3: & Conscious sedation \\
Level 3 (a) & $-\quad$ Oral or inhalational medications with a sedative effect \\
Level 3 (b) & $-\quad$ Parenteral medications with a sedative effect \\
\hline Level 4: & Regional anaesthesia \\
\hline Level 5: & General anaesthesia \\
\hline * Pain management should be defined according to the highest level of intervention used to control pain if combined therapies are used.
\end{tabular}

* Pain management should be defined according to the highest level of intervention used to control pain if combined therapies are used.

\section{Domain 2: Setting}

Setting is defined in alignment with the "International Association for Ambulatory (Day) Surgery (IAAS) Suggested International Terminology and Definitions" and according to the level of pain management that is feasible in the facility where the hysteroscopic procedure is performed (1).

\begin{tabular}{|l|l|}
\hline Office $^{*}$ & $\begin{array}{l}\text { The hysteroscopic procedure is performed in a medical practitioner's professional premises where } \\
\text { pain control up to level 3(a) can be administered. }\end{array}$ \\
\hline Outpatient Clinic & $\begin{array}{l}\text { The hysteroscopic procedure is performed in a health care facility for the management of outpatients } \\
\text { e.g. hospital, community clinic or a freestanding surgical centre where pain control up to level 3(a) } \\
\text { can be administered. }\end{array}$ \\
\hline Operating Room & $\begin{array}{l}\text { The hysteroscopic procedure is performed in a fully equipped operating theatre where pain control } \\
\text { up to level } 5 \text { can be administered }\end{array}$ \\
\hline
\end{tabular}

\section{Domain 3: Model of care}

Model of care is defined according to the need for admission, the length of stay and type(s) of facility (in accordance with the IAAS (1) in relation to the hysteroscopic procedure undertaken.

\begin{tabular}{|l|l|}
\hline Office & $\begin{array}{l}\text { The model of care will be considered as "office" when the patient arrives and leaves a medical } \\
\text { practitioner's professional premises, which provides an appropriately designed, equipped and serviced } \\
\text { room(s), on the same calendar day. }\end{array}$ \\
\hline Outpatient $^{*}$ & $\begin{array}{l}\text { The model of care will be considered as "outpatient" when the patient arrives and leaves the facility } \\
\text { (outpatient clinic / department of a hospital, community clinic or a freestanding surgical centre (public } \\
\text { or private)) on the same calendar day. }\end{array}$ \\
\hline Ambulatory & $\begin{array}{l}\text { The model of care will be considered as "ambulatory" when the patient undergoing the hysteroscopic } \\
\text { procedure is admitted to a facility (hospital or surgical centre) and discharged on the same calendar } \\
\text { day. }\end{array}$ \\
\hline Extended Recovery & $\begin{array}{l}\text { The model of care will be considered as "extended recovery" when the patient is admitted to a facility } \\
\text { (hospital or surgical centre) with discharge the following calendar day with a length of stay of less } \\
\text { than } 24 \text { hours. }\end{array}$ \\
\hline Inpatient & $\begin{array}{l}\text { The model of care will be considered "inpatient" when the patient is admitted to a facility (hospital } \\
\text { or surgical centre) and discharged not sooner than the following calendar day, with a length of stay of } \\
\text { at least } 24 \text { hours. }\end{array}$ \\
\hline * In the United States the term office and outpatient are used interchangeably as regards the model of care
\end{tabular}

\section{Domain 4: Type of procedure}

Type of hysteroscopic procedure is defined according to whether it is diagnostic or operative, where it has therapeutic value

\begin{tabular}{|l|l|}
\hline Diagnostic hysteroscopy & $\begin{array}{l}\text { A hysteroscopic procedure to evaluate the uterine cavity / cervical canal with or without targeted } \\
\text { biopsy (under hysteroscopic visualisation). }\end{array}$ \\
\hline Operative Hysteroscopy & $\begin{array}{l}\text { A hysteroscopic procedure to treat uterine pathology, or symptoms arising from the uterus, under } \\
\text { direct hysteroscopic visualisation using hysteroscopic instruments. }\end{array}$ \\
\hline
\end{tabular}
** "The use of hysteroscopy is not intended for the evaluation and management of the patient with cervical cancer or its precursors.
considered an operative hysteroscopy according to the proposed classification. However, studies describing such uterine procedures should report pain management, setting and
model of care as described in the preceding sections.

Domain 5: Approach of the hysteroscopic procedure

Approach to the hysteroscopy is defined according to whether vaginal instrumentation is used or not

\begin{tabular}{|l|l|}
\hline Vaginoscopic & $\begin{array}{l}\text { The hysteroscope is steered into the cervical canal without the use of a speculum and/or stabilising } \\
\text { forceps to facilitate the visualisation of the cervix and entry into the cervical canal and uterine cavity. }\end{array}$ \\
\hline Speculum assisted & $\begin{array}{l}\text { The hysteroscope is steered into the cervical canal with the use of a speculum and/or stabilising } \\
\text { forceps to facilitate the visualisation of the cervix and entry into the cervical canal and uterine cavity. }\end{array}$ \\
\hline
\end{tabular}

\section{Reference}

Lemos P, Jarrett P, Phillip B, eds (2006). Day surgery: development and practice. London: International Association for Ambulatory Surgery. ISBN 9892002342 Retrieved 03/24/2020. 